\title{
Effect of Ce Addition and Deformation on the Microstructure and Hardness of (Al- Si-Mg) A356 Type Alloys
}

\author{
H. M. Medrano-Prieto ${ }^{1}$, C.G. Garay-Reyes ${ }^{1}$, M. C. Maldonado-Orozco ${ }^{1}$, R. Martínez-Sánchez ${ }^{1}$. \\ 1. Centro de Investigación en Materiales Avanzados (CIMAV), Laboratorio Nacional de Nanotecnología, \\ Miguel de Cervantes No. 120, Chihuahua, Chih., México.
}

A356 aluminum alloy is based in Al-Si system, the major characteristics are high castability due to Si content, corrosion resistant, excellent strength/weight ratio and optimal combination of strength and ductility. The principal applications are in the automotive, aerospace and military industries. The most important element in addition to $\mathrm{Si}$ is $\mathrm{Mg}$, the optimums mechanical properties of A356 aluminum alloy are obtained after an aging heat treatment due to a precipitation of a $\beta-\mathrm{Mg}_{2} \mathrm{Si}$ semi-coherent and metastable phases. The typical microstructure of A356 Aluminum alloy in as cast condition is conformed by Al- dendrites, eutectic Silicon particles, Fe intermetallics and $\mathrm{Mg}_{2} \mathrm{Si}$ equilibrium phases [1]. It has been reported that rare earths additions have a positive effect on hardness property [2]. Additionally, the modification of microstructure because hot forming process in Al-Si alloy, enhances the mechanical properties [3-5].

This work is focused on the modification (variation) of microstructure by the Ce additions, hot deformation and heat treatments in A356 Al alloy.

Variations in the microstructure were characterized by SEM and TEM.

The A356 alloy and those modified with Ce were deformed at $350{ }^{\circ} \mathrm{C}$, solution heat treated at $535{ }^{\circ} \mathrm{C}$ for 3,5 and $7 \mathrm{~h}$, quenching in hot water at $60^{\circ} \mathrm{C}$ and aged at $180^{\circ} \mathrm{C}$ for $0.5,3,5,10 \mathrm{~h}$. The Ce addition $(0.1$, 0.3 and 0.5 wt. \%) and the deformation ratio $50 \%$ to the A356 alloy have an important effect on the microstructure; mainly in the morphology, size and distribution of $\beta-\mathrm{Mg}_{2} \mathrm{Si}$ precipitates formed during aging heat treatment.

The figure 1, show the elemental mapping of the A356 alloy with Ce addition, deformed and solubilized, where is observed the distribution of main elements in the A356 alloy, the change in the microstructure due to the hot deformation process on the morphology of the dendrites and the modification of interdendritic Si phase due to the solution heat treatment, as well as the presence of Ce rich phases and the homogeneous distribution of $\mathrm{Mg}$.

The figure 2 show a STEM-bright field (BF) micrographs of a) reference alloy and $b$ ) the modified alloy with $0.3 \mathrm{wt} \% \mathrm{Ce}$, it is evident the effect of the Ce addition in the precipitation kinetics of $\beta-\mathrm{Mg}_{2} \mathrm{Si}$ precipitates, in the micrograph a) it is observed a high density number of precipitates finely dispersed in aluminum matrix with a noodles-like morphology, length from 15 to $25 \mathrm{~nm}$ and thickness of 2.9 a 4.7 $\mathrm{nm}$, in the b) micrograph is observed a difference in size of $\beta-\mathrm{Mg}_{2} \mathrm{Si}$ which are bigger than those presented in the Ce free alloy, with thickness of $3.5 \mathrm{~nm}$, length of 12 to $50 \mathrm{~nm}$ and low density number of precipitates. 
References:

[1] Wang, Q.G., Met. Mater. Trans. A 34 (2003) p. 2887-2899.

[2] D.H. Xiao et al, J. Alloys Compd 352 (2003) p. 84-88.

[3] D.G. Mallapura, K. Rajendra Udupaa, S.A. Korib, Mater. Sci. Eng. A. 528 (2011) p. 4747-4752

[4] Kyuhong Lee a, Yong Nam Kwon b, Sunghak Lee a, J. Alloys. Compd, 461 (2008) p. 532-541.

[5] A. Dodangeh, M.Kazeminezhad n, H.Aashuri, Mater. Sci. Eng. A. 558 (2012) p. 371-376
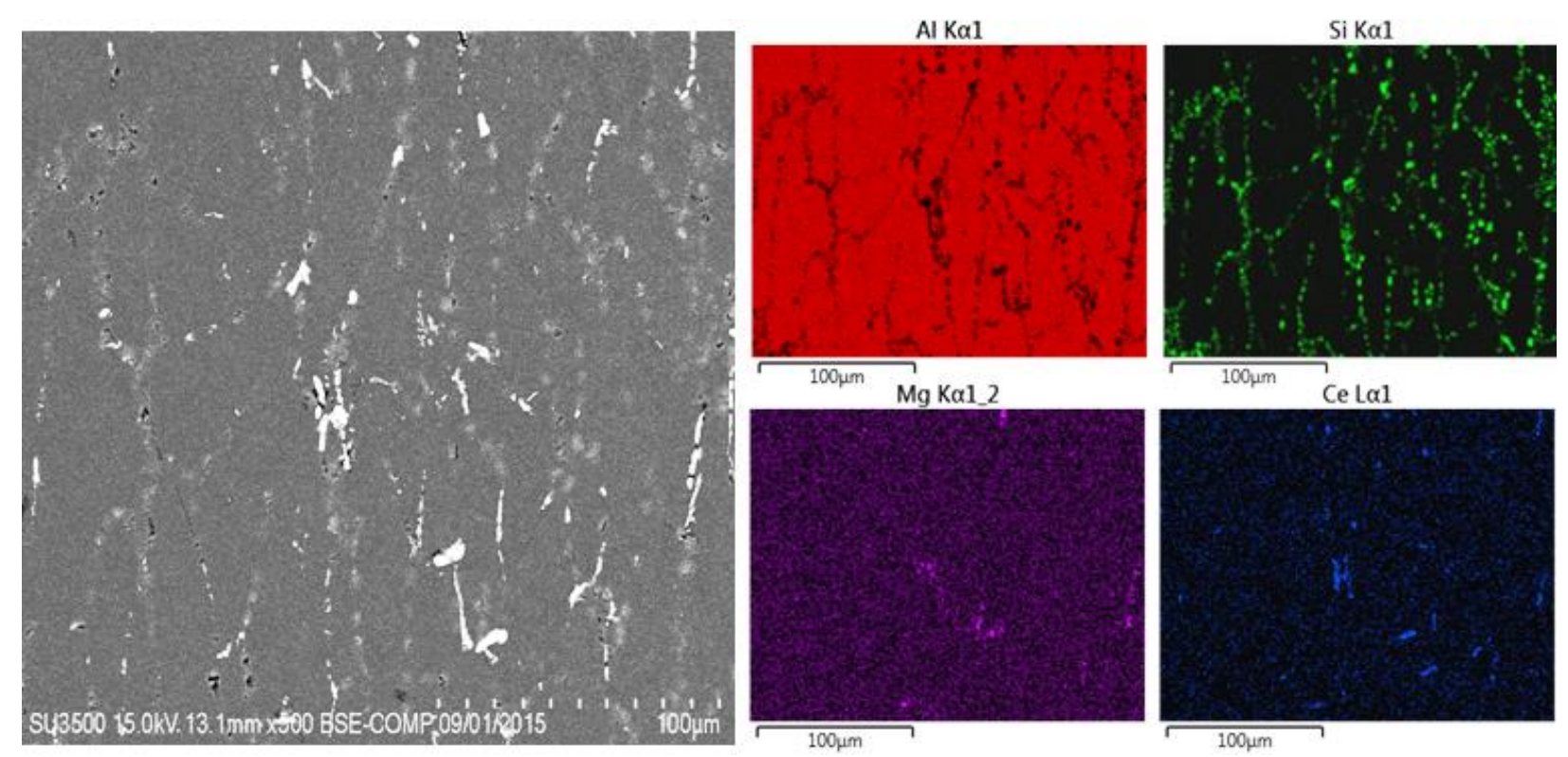

Figure 1. MEB Micrograph and elemental mapping of A356 alloy modified with 0.3 wt. \% Ce, deformed and solubilized for $5 \mathrm{~h}$ at $535{ }^{\circ} \mathrm{C}$
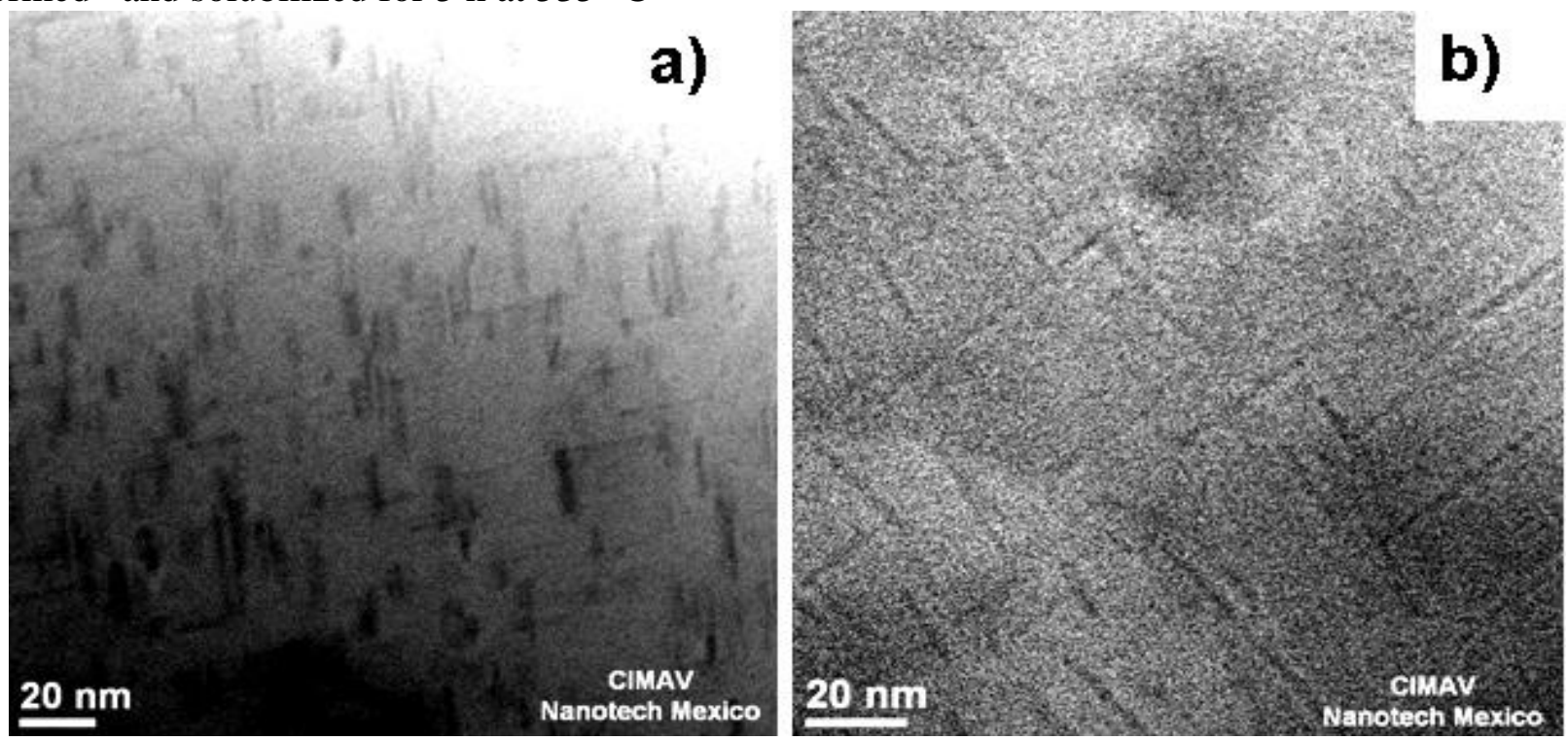

Figure 2. TEM Micrographs of A356 deformed alloys after $7 \mathrm{~h}$ of solution treatment at $535{ }^{\circ} \mathrm{C}$ and aging heat treatment for $3 \mathrm{~h}$ at $180{ }^{\circ} \mathrm{C}$. a) Reference alloy, b) modified alloy (0.3 wt. \% Ce). 